\title{
Curriculum y colonialidad. Repensando el curriculum desde las Epistemologías del Sur
}

\author{
Curriculum and colonialism. Rethinking the curriculum from the \\ Epistemologies of the South
}

\author{
Maricruz Mendez Karlovich \\ mmkarlovich@gmail.com \\ Instituto de Curriculum y Evaluación de la Facultad de \\ Ciencias Sociales, Universidad Nacional de Lomas de \\ Zamora, Argentina
}

Recepción: 16 Abril 2020

Aprobación: 29 Marzo 2021

Publicación: 01 Abril 2021

Cita sugerida: Mendez Karlovich, M. (2020). Curriculum y colonialidad. Repensando el curriculum desde las Epistemologías del Sur. Archivos de Ciencias de la Educación, 14(18), e089. https://doi.org/10.24215/23468866e089

\begin{abstract}
Resumen: El siguiente ensayo procura la construcción y socialización de algunas categorías analíticas generales que permitan diseñar, implementar y evaluar diferentes materiales curriculares desde la perspectiva de las epistemologías del Sur. Esta construcción se nutre de las prácticas pedagógicas y de múltiples espacios de reflexión colectiva entre lxs diversxs actores que habitamos los procesos de enseñanza y de aprendizaje y procuramos sociabilidades "otras" que permitan mayor justicia cognitiva y espacios educativos más participativos y cooperativos. Luego del desarrollo de las categorías y de la construcción de condiciones para que posibilidades "otras" puedan generarse, emerge la concepción del curriculum como espacio de restitución frente a la creación de ausencias que caracteriza a la situación de la que parte el análisis.
\end{abstract}

Palabras clave: Curriculum, Colonialidad, Epistemologías del Sur, Justicia cognitiva.

\begin{abstract}
The following text aims to construct and socialize some general analytics categories that all owes to design, implement and evaluate different curricular materials from the stand point of the Epistemologies of the South. This construction draw son pedagogical practices and multiple spaces for collective reflection among different take holders that are engaged in teaching and learning processes and try to build "others" social skills which allow major cognitive justice and more participatory and cooperative educative environments. After developing categories and constructing conditions so that "other" possibilities may be produced, a conception of the curriculum as an environment of restitution facing the creation of absences that characterizes the situation from which the analysis starts will emerge.
\end{abstract}

Keywords: Curriculum, Colonialism, Epistemologies of the South, Cognitive Justice.

\section{INTRODUCCIÓN}

El siguiente ensayo pretende socializar algunas categorías analíticas generales que provienen del análisis de diferentes aportes que ofrecen las Epistemologías del Sur ${ }^{1}$ (De Sousa Santos, 2018a) para reflexionar sobre 
el campo curricular ${ }^{2}$. Se espera que estas categorías sirvan como dispositivo para el diseño, implementación y evaluación de materiales curriculares promoviendo otras posibilidades de ser y estar en el mundo y habilitando encuentros de enseñanza y de aprendizaje más participativos, solidarios y cooperativos. Para esto se recuperan producciones vinculadas a la educación y la colonialidad en las que se aborda la colonialidad del saber, las geopolíticas y los legados coloniales del conocimiento que dan cuenta de las relaciones de poder que atraviesan los procesos de transmisión cultural.

A su vez, se señala la posibilidad de descolonizar el curriculum ${ }^{3}$ a partir de la necesidad de rescatar miradas sobre América Latina a partir de América Latina y el diálogo como metáfora de la interculturalidad latinoamericana. También se recuperan aportes de la pedagogía y teoría curricular latinoamericana y de la pedagogía crítica.

Luego, se socializan diferentes categorías analíticas que procuran colaborar en el marco de iniciativas descolonizadoras del curriculum para pensar sobre su diseño, implementación y evaluación desde una mirada "otra" que habilite presencias creadas como ausentes y espacios de mayor copresencia.

En este marco, se presentará a la colonialidad curricular, la potencialidad curricular, el costo de oportunidad curricular y la radicalidad del contenido como categorías que nos permitan repensar el campo a partir de los aportes teóricos y experiencias desde las propias comunidades y vincularlo a las prácticas pedagógicas para promover una traducción real en los espacios de enseñanza y de aprendizaje.

Finalmente, se aborda el curriculum como un espacio de restitución donde esas ausencias creadas se recuperan y, a partir del trabajo de reflexión e historización que permite establecer las relaciones de poder que las invisibilizaron, pueden ser restituidas.

\section{EDUCACIÓN Y COLONIALIDAD}

Varias producciones pusieron en relación a la educación y la colonialidad dando cuenta del atravesamiento de la matriz y lógica occidental en los procesos de producción de conocimientos y en los encuentros de enseñanza y de aprendizaje.

Edgardo Lander (2000) aborda la colonialidad del saber destacando el rol de las ciencias sociales como naturalizador de un orden y el neoliberalismo como discurso hegemónico de un modelo civilizatorio en el cual subyacen supuestos y valores de la sociedad liberal moderna, esgrimida como horizonte único para el resto de las sociedades. Así, la concepción de ser humano, de riqueza, naturaleza, historia, progreso, conocimiento y buena vida, son percibidos desde esta visión, invisibilizando otras posibles. Lander historiza esta construcción y delinea caminos para su deconstrucción.

Tadeu Da Silva (2001) reagrupa la producción del campo curricular y categoriza las distintas teorías según tradicionales, críticas y poscríticas, entre las que ubica a las poscoloniales. Señala que la perspectiva poscolonial del curriculum "debería estar muy atenta a las formas aparentemente benignas de representación del Otro presentes en todos los curricula contemporáneos" (p. 161), a la vez que destaca que es una perspectiva que no separa las cuestiones de conocimiento, cultura y estética de las cuestiones de poder, política e interpretación.

Antunes Prado (2004) analiza la educación y la colonialidad en América Latina para comprender las formulaciones sobre educación tal como fueron y siguen siendo producidas en algunos movimientos revolucionarios en la región. Luego de retomar las posiciones de Martí, Mariátegui y Bolívar, entre otros, para llegar a Freire, propone el rescate de las miradas sobre América Latina a partir de América Latina desde la óptica del pensamiento fronterizo sobre educación, una pedagogía para la región a partir de la diferencia colonial.

Por otra parte, Peñuela (2009) en su artículo sobre la pedagogía decolonial y educación comunitaria encuentra en esta perspectiva pedagógica una crítica al discurso pedagógico moderno y una posibilidad investigativa de problematizar las prácticas de formación docente. La autora se pregunta por lo ético y lo 
político en las prácticas pedagógicas de formación docente para situarlas desde una crítica a la epistemología del saber como poder, es decir,

una crítica a la manera en que el poder es ejercido desde el punto en que tradicionalmente se ubica el conocimiento científico asumido como válido, aunque en muchos casos no legítimo, y en el cual, consecuentemente, quien sabe más, puede más (p. 42).

A su vez, explicita la necesidad de la pedagogía de generar posibilidades de pensamientos otros que permitan fronterizar el pensamiento hegemónico a manera de proyectos contra-hegemónicos, para posteriormente permitir que lxs sujetxs se posicionen críticamente.

Díaz (2010) parte de los aportes del programa modernidad / colonialidad con el fin de esbozar condiciones de posibilidad en torno a una pedagogía en clave decolonial poniendo en diálogo los saberes propios de la pedagogía con las ideas provenientes del giro decolonial. Destaca así como elementos significativos la comprensión crítica de la historia, el reposicionamiento de prácticas educativas de naturaleza emancipatoria y el descentramiento de la teoría colonial. En el campo específico de lo curricular, en esta perspectiva se plantea la tensión por dilucidar cómo producir, potenciar y hacer circular saberes que no se hallen estrictamente circunscritos a los mecanismos convencionales de producción de conocimiento de la modernidad.

Dietz y Mateos (2011) analizan la interculturalidad y la educación intercultural en México y establecen una tipología de las tendencias internacionales en relación a la pedagogización de la diversidad cultural, entre las que incluyen el "educar para descolonizar". Señalan que en el contexto latinoamericano, en los últimos años, el discurso intercultural fue apropiado por diversos actores académicos y políticos generalmente cercanos a los movimientos indígenas y que hubo dos innovaciones: "un giro poscolonial y/o descolonial” y la metáfora del diálogo como una característica central de la interculturalidad latinoamericana (p.57).

Catherine Walsh lleva adelante varias producciones sobre lo decolonial y los procesos pedagógicos, aquí recuperamos algunos de ellos. En su artículo sobre interculturalidad, colonialidad y educación (Walsh, 2007) destaca la necesidad de construir procesos educativos descolonizadores, reflexionando sobre las geopolíticas y los legados coloniales del conocimiento a partir del entendimiento de la interculturalidad como proyecto político-epistémico.

Walsh (2009) analiza las luchas (de)coloniales de nuestra época a través de la vinculación entre interculturalidad, estado y sociedad. Señala la educación, junto al derecho, como los campos que más sirvieron a las necesidades uniformadoras del Estado y en defensa del capitalismo como vínculo constitutivo de la colonialidad del poder. Sin embargo, destaca la importancia del sistema educativo como

una de las instituciones sociales más importantes para construir la interculturalidad, ya que es la base de la formación humana e instrumento no sólo de mantenimiento de una sociedad sino de su crecimiento, transformación y liberación y del reconocimiento de todas sus potencialidades civilizatorio-humanas (p.183).

Walsh (2008) analiza la etnoeducación e interculturalidad en perspectiva decolonial dando cuenta de la necesidad de pensar, construir y accionar ambas dimensiones en el marco de la lucha de los pueblos afrodescendientes hacia afuera (los Estados que históricamente negaron su existencia) y hacia adentro de sus propias comunidades para fortalecer la pertinencia, los conocimientos y las prácticas y perspectivas de vida arraigadas a la ancestralidad, territorialidad y cimarronaje pasado y presente.

Por su parte, Plá (2016) compara la narración acerca de los procesos de conquista y colonización en Chile, México, Ecuador y Bolivia en sus diseños curriculares de la educación obligatoria para observar el

potencial deconstructivo de las relaciones simbólicas de poder en las narraciones históricas y analizar qué proyecto educativo responde mejor a las exigencias de reconocimiento de los grupos subalternos como parte de la lucha por la justicia social en estos cuatro países latinoamericanos (p. 54).

Benedito, Santos y Souza (2016) analizan el curriculum y las relaciones etnicorraciales a partir de la implementación de la disciplina Historia de la cultura afro-brasilera en el municipio de Jequié en Bahia 
promovida por la Ley 10639/03. Se expone que la creación de la disciplina analizada puede haber contribuido a que los discentes negros y no negros de las llamadas clases populares de las escuelas públicas jequienses se hayan empoderado y apropiado de conocimientos importantes para la comprensión de la sociedad brasilera.

Bergamaschi y Menezes (2016) analizan los procesos propios de educación del pueblo guaraní y si bien no mencionan a la colonialidad como dimensión de análisis, previenen sobre no intentar encajar a la escuela guaraní en un modelo de enseñanza occidental, y sobre la educación intercultural como encuentros cosmológicos entendidos en un camino de cuerpo y espíritu integrados en una misma dimensión.

Cunha y Da Silva (2016) desde un enfoque posestructuralista discuten las articulaciones políticas que se forman en torno al significante curriculum y de qué manera éstas influyeron en el proyecto de la base nacional curricular de Brasil. Argumentan que el curriculum que se adapte a un padrón y busque construir un fundamento único tiende a ignorar los saberes otros presentes en las experiencias de lxs sujetxs sociales, de su cultura y de su historia.

Recuperamos también las producciones de De Sousa Santos que a través de la Epistemología del Sur propone distanciarnos del pensamiento eurocéntrico para poder permitir que lo impensable sea pensado y que realidades que son ignoradas o invisibilizadas y consideradas no existentes por la tradición crítica eurocéntrica, tengan lugar.

De Sousa Santos (2018a) señala que las Epistemologías del Sur ocupan el concepto de epistemología con el fin de resignificarlo como un instrumento para interrumpir las políticas dominantes del conocimiento, teniendo como objetivo identificar y valorizar lo que a menudo ni siquiera aparece como conocimiento a la luz de las epistemologías dominantes. Aclara que no busca reemplazar las epistemologías del Norte por las del Sur sino superar el dualismo normativo existente y la dicotomía jerárquica entre el Norte y el Sur. Promueve la valoración y afirmación de las diferencias que queden después de que las jerarquías hayan sido eliminadas, entendiendo que no hay justicia global sin justicia cognitiva global. A su vez, el sociólogo portugués expone las limitaciones de la teoría crítica desarrollada dentro de la tradición occidental para señalar la necesidad de distanciarse epistemológicamente y teóricamente en miras de descolonizar el saber para reinventar el poder. Describe cómo la epistemología occidental dominante fue construida a partir de las necesidades de la dominación capitalista y colonial con base en el pensamiento abismal (De Sousa Santos, 2010).

Este autor analiza también la Universidad moderna y la posibilidad de refundarla en miras de un futuro poscapitalista, poscolonial y pospatriarcal. Sería el movimiento hacia una "pluriversidad" que será una universidad polifónica por ejercer su compromiso en forma plural y comprometida por su vínculo con las luchas sociales (De Sousa Santos, 2018b).

Finalmente, recuperamos de la teoría curricular latinoamericana aportes de De Alba y de Puiggrós, quienes promueven la recuperación de las alternativas negadas. A su vez, desarrollos desde la pedagogía crítica como los de Giroux y Apple nos invitan a pensar en otras lecturas posibles y en un curriculum con diversidad de voces. Entre los aportes teóricos para pensar los procesos curriculares desde Latinoamérica, encontramos a la pedagoga mexicana Alicia de Alba (1995) y su concepción de curriculum como una síntesis cultural (conocimientos, valores, costumbres, creencias, hábitos) que conforma una propuesta político educativa pensada e impulsada por diversos grupos y sectores sociales, cuyos intereses son diversos y contradictorios, aunque algunos tiendan a ser dominantes o hegemónicos, y otros tiendan a oponerse y resistirse a tal dominación o hegemonía. A esta síntesis se arriba a través de diversos mecanismos de negociaciones e imposiciones sociales, dando cuenta de las relaciones de poder que rigen estas luchas. Esta mirada nos permite inscribir al curriculum en un contexto de disputas.

Por otra parte, la pedagoga argentina Adriana Puiggrós en su obra Sujetos, Disciplina y Curriculum en los orígenes del sistema educativo argentino (1990) recupera las alternativas pedagógicas negadas por el discurso oficial y da cuenta de significados ocultados o no registrados por los textos. Busca así resignificar el sujeto pedagógico en la historia de la educación argentina y dar cuenta de la distancia entre el sujeto propuesto 
por las alternativas pedagógicas y el de la pedagogía oficial, permitiéndonos pensar en estas brechas que se construyen y en las diversas pedagogías que fueron construidas como no existentes.

El referente de la pedagogía crítica Giroux en su desarrollo sobre la Pedagogía Fronteriza o Pedagogía de los límites promueve el desarrollo de formas de transgresión a partir de las cuales sea posible desafiar y redefinir los límites existentes, produciendo nuevas formas de conocimiento, subjetividad e identidad a partir del desarrollo de condiciones en las que los estudiantes puedan leer y escribir dentro y en contra de los códigos culturales existentes. Giroux presenta a los textos como insumo para el trabajo con los contenidos educativos y propone una lectura descentralizada para analizarlos desde su dimensión histórica y social e identificando las lecturas heredadas. En este marco, promueve lecturas diversas enfocándose en la manera en que distintos destinatarios pudieron responder a ellos, destacando así las posibilidades de leer contra, dentro y fuera de los límites establecidos (González Martínez, 2006).

Por último, Apple en Ideología y Currículo (1979) analiza la forma en que la escuela reproduce la estructura ideológica de las clases dominantes de la sociedad y las formas de control social y cultural a partir del concepto de hegemonía que le permite relacionar la cultura, el poder y la economía. A su vez, da cuenta de que el curriculum oculto esconde el conflicto, al igual que las disciplinas, en su forma de presentarse. En su obra junto a Beane (2000) Escuelas Democráticas señalan que éstas deben contar con estructuras y procesos democráticos, promover la participación de la comunidad, la inclusión, la búsqueda del bien común y la cooperación. Este curriculum democrático debe incluir distintas voces y favorecer la interpretación crítica de las y los estudiantes.

Estos antecedentes nos permitieron conocer producciones que vinculan lo educativo con la colonialidad del saber y aportes desde la pedagogía y teoría curricular latinoamericana y la pedagogía crítica que nos orientan en la reflexión sobre el campo curricular tanto en su etapa de diseño como de implementación, desarrollo y evaluación para promover prácticas pedagógicas desde una Epistemología del Sur.

\section{CONSTRUYENDO CATEGORÍAS ANALÍTICAS Y PROPONIENDO ENTORNOS PARA CONSTRUIR Y RECONSTRUIR UNOS CURRICULA “OTROS”}

A partir de los aportes que vinculan el campo educativo y la colonialidad procuraremos generar algunas categorías al servicio de las prácticas vinculadas al campo curricular para construirlo y reconstruirlo desde la perspectiva de las Epistemologías del Sur (De Sousa Santos, 2018a). En este marco, se presentará a la colonialidad curricular, la potencialidad curricular, el costo de oportunidad curricular y la radicalidad del contenido como categorías que nos permitan repensar el campo a partir de los aportes teóricos y experiencias desde las propias comunidades y vincularlo a las prácticas pedagógicas para promover una traducción real en los espacios de enseñanza y de aprendizaje.

La colonialidad curricular da cuenta de que la conformación de los saberes tiene una impronta eurocéntrica, capitalista y, por lo tanto, colonial, ya que fue en la Modernidad y a partir de los procesos de conquista, despojo y expropiación donde se inscriben las referencias de origen de la matriz actual. Este concepto dialoga con la colonialidad del poder (Quijano, 2000) ${ }^{4}$ y del saber (Lander, 2000) y evidencia la necesidad de trabajar desde la sociología de las ausencias (De Sousa Santos, 2018a) para identificar las maneras en que el colonialismo opera junto al capitalismo y al patriarcado para producir ciertos grupos de personas y formas de vida social como "no existentes, invisibles, radicalmente inferiores o peligrosos, en suma, como descartables o amenazantes" (p. 307).

Hay que preguntarse: ¿cómo descolonizar la mente "cuando no se puede ver claramente, cuando la memoria de lo que fue y de lo que podría haber sido fue completamente distorsionada? ¿Cómo descolonizar si la imagen del mundo es colonial?” (Thiongó citado en Antonacci, 2016, p. 491) 
A partir de descolonizar los curricula se podrá visibilizar saberes que se encuentran silenciados. Así, saberes, actores y procesos plurales invisibilizados de otras culturas podrán aparecer y estar presentes de manera contemporánea y simultánea entre sí. En esta línea, Lao-Montes (2013) aboga por

la transformación de los currículos hacia la inclusión de las memorias, historias y expresiones culturales Afro, a través de programas de estudios negros, afrodiaspóricos y africanos, así como mediante una transformación de las perspectivas epistémicas y pedagógicas eurocéntricas y occidentalistas, al igual que de las prácticas racistas a través de todos los tejidos institucionales (p. 76).

El modelo liberal de la organización de la propiedad, del trabajo y del tiempo se instala como única forma de vida posible, superior y universal, desconociendo otras realidades que existen y que la lógica colonial construye como ausente. "Aún hoy existen muchos sistemas de propiedad comunal en una gran cantidad de lugares del mundo, sobre todo en África y entre las comunidades indígenas de Latinoamérica" (Caffentzis y Federici, 2015 , p. 55). Desconocer estas realidades nos impide poner en tensión la propiedad privada y desnaturalizar e historizar su instalación como único sistema de propiedad viable. Lo mismo ocurre con la organización del trabajo y del tiempo.

En las prácticas pedagógicas esto puede generar reales espacios de reflexión y debate sobre la colonialidad que atraviesa al curriculum en los espacios de enseñanza y de aprendizaje. Dar cuenta de las presencias coloniales permitirá construir horizontes de posibilidad frente a las ausencias. A a su vez, historizar esas presencias coloniales permitirá establecer las relaciones de poder en que se encuentran inscriptas, dar cuenta de la relación entre poder y saber, y reflexionar sobre la alteridad y quienes son lxs "otrxs" que aparecen y cuáles no y las características que estas presencias y ausencias asumen.

Alentar desde las prácticas procesos de investigación y de reconocimiento hacia otras formas de organizar la propiedad, el trabajo y el tiempo, en la historia y en la actualidad, permite visibilizar otras posibilidades construidas como no existentes, ampliando los horizontes de posibilidades de diversas formas de ser y estar en el mundo.

La potencialidad curricular es la capacidad que se tiene desde el campo curricular de poner en tensión las relaciones de poder existentes en la sociedad que reproducen la colonialidad y traccionar, así, hacia su superación y/o modificación. Desde esta perspectiva se vincula el campo curricular y sus posibilidades estratégicas de intervención, con las luchas sociales que se libran por la transformación social de un orden que es considerado injusto, desigual, capitalista, patriarcal y colonial. A su vez, se vincula con las políticas de reconocimiento y la visibilización de diferentes identidades que fueron históricamente silenciadas / ocultadas.

La potencialidad curricular enfatiza las múltiples posibilidades que tiene el curriculumpara construir otras realidades e impactar en las prácticas, de las que se alimenta para su conformación, construyendo un ciclo interdependiente entre el diseño, la implementación y su permanente transformación a partir de las acciones de lxspropixs actores que participan de los procesos de enseñanza y de aprendizaje.

Esta potencialidad curricular está vinculada a la sociología de las emergencias (De Sousa Santos, 2018a) que da cuenta de las nuevas potencialidades y posibilidades para la transformación social, anticapitalista, anticolonialista y antipatriarcal que emerge en el campo de las experiencias sociales que son recuperadas y fueron previamente descartadas. Esta potencialidad requiere de un diálogo cercano con las experiencias sociales para poder articular esas demandas, conquistas y horizontes construidos con los saberes y horizontes que se construyen desde los espacios de enseñanza y aprendizaje. A su vez, promueve la ecología de saberes (De Sousa Santos, 2018a) que es el reconocimiento de la copresencia de diferentes saberes, inscriptos en las diversas formas de ser y estar en el mundo, y pone de relieve "la necesidad de estudiar las afinidades, divergencias, complementariedades y contradicciones entre ellos (los saberes) para maximizar la efectividad de las luchas de resistencia contra la opresión" (p. 295).

Antonacci (2016), al hacer referencia a las leyes que interpelan lo curricular obligando a las escuelas a incorporar contenidos vinculado con temáticas invisibilizadas, da cuenta de las potencialidades que conllevan 
estas acciones para sacudir las bases de lo instituido y la posibilidad que abren al conducir a descubrimientos $\mathrm{y}$ a discusiones e intercambios entre universos africanos, indígenas y europeos.

En las comunidades afrodescendienteshay cosmovisiones y prácticas de vida que tienden a combinar producción de la vida material con elementos culturales. Estas han sido conceptualizadas y convertidas en paradigmas explícitos de etnodesarrollo sostenible, ecológicamente armónico, y fundamentado en formas propias de convivencia, redistribución y autogobierno. En este momento de crisis se abren posibilidades de cambio que realzan la importancia y viabilidad de dichas racionalidades, prácticas y propuestas de buen vivir (Lao-Montes, 2013, p. 76)

En las prácticas pedagógicas, construir el compromiso hacia la potencialidad curricular transforma a los actores que habitan el campo en hacedores reales de la cultura y en agentes activos en la construcción del conocimiento, a partir del reconocimiento del otro y de las experiencias y saberes que lo atraviesan y lo constituyen. Promover desde las prácticas, espacios de diálogo entre diversidad de racionalidades, prácticas, saberes y memorias, permite construir posibilidades de relaciones de copresencia, complementariedad y reciprocidad no sólo entre estos saberes sino entre las comunidades que los habitan, desalentando las relaciones de desigualdad y jerarquía que caracterizan a estos vínculos.

El costo de oportunidad curricular viene a dar cuenta de los costos que conlleva la construcción de ausencias a partir de la vigencia de la colonialidad curricular como espacio de construcción de los saberes. La construcción de estas ausencias tiene costos vinculados a las múltiples pérdidas de saberes, conocimientos, relaciones con las que no tenemos contacto y que impiden el conocimiento y reconocimiento de otras formas de ser y estar en el mundo que podrían abonar a los desafíos actuales de las sociedades y que no podemos ver porque las creamos como ausentes.

El no reconocer otros modos de ser y estar en el mundo impide problematizar el propio. Lenkersdorf (2003) al relatar la experiencia intercultural junto a los tojolabales da cuenta del descubrir que el "Nosotros" representa un principio organizativo para esa comunidad mientras que el individualismo competitivo o la competitividad individualista hace las veces de tal principio en la sociedad dominante. Muchas veces es a partir del reconocimiento de lo "otro" que se percibe lo "propio".

En las prácticas pedagógicas, reflexionar sobre los costos de oportunidad curricular permite poner en evidencia los saberes que portan lxs sujetxs que habitan los espacios de enseñanza y de aprendizaje y detectar qué de esos saberes son recuperados por la escuela y cuáles son invisibilizados, como parte de los costos que la colonialidad curricular acarrea. A partir de ahí, debatir sobre las experiencias, conexiones y vínculos que esos saberes habilitan y que eran marginados hasta el momento. Esta instancia de reconocimiento y puesta en relación es parte del camino descolonizador.

Será necesario construir en los espacios pedagógicos, entornos que promuevan la construcción desde los márgenes para que lxssujetxs que los habitan puedan compartir esos saberes y que éstos sean recogidos y puestos en valor y en diálogo.

El mismo proceso de reflexión y debate colectivo sobre las presencias y ausencias, sobre la lógica colonial que atraviesa el curriculum en general, incluso las relaciones que impone entre el conocimiento y su producción y las sociabilidades que promueve, forman parte del camino hacia la descolonización.

¿Cómo pensar curricula, contenidos y metodologías, cómo formular políticas y planificar programas educativos sin incorporar los estrechos vínculos entre las condiciones en que los educando reproducen sus existencias y sus aprendizajes humanos? (Arroyo, 2003, p.33)

La radicalidad del contenido es la potencialidad que existe en la relación entre los contenidos a enseñar y el impacto directo que tienen en las luchas que lleva adelante esa comunidad y en sus procesos identitarios. Los contenidos de carácter radical son aquellos que se vinculan con lxs sujetxs y las comunidades a partir de los propios desafíos que enfrentan. Estos contenidos no están solo vinculados con saberes teóricos, sino que abonan las luchas a partir del reconocimiento de otras sociabiliades, otras relaciones insurgentes entre actores 
diversos, otras formas de organización social, política y económica y promueven diálogos más concretos entre la educación y la transformación social.

Gutierrez y Salazar Lohman (2015) abordan la reproducción comunitaria de la vida y expresan que la trans-formación social deviene en el despliegue de la capacidad humana de producir y reproducir formas colectivas de habitar el mundo desde otro lugar que no es el de la dominación, al explotación y el despojo, y arroja los interrogantes sobre cómo desplegar colectivamente la capacidad, específicamente humana, de transformación social, qué categorías, nociones e ideas resultarían fértiles para pensar en ellos y cuáles bloquearían el pensamiento, entre otros. Frente a estos interrogantes / desafíos la escuela, a partir del campo curricular, puede posicionarse y traccionar hacia la incorporación de estas categorías que promuevan la transformación y desnaturalicen los modos de reproducción de la vida hegemónicos.

La radicalidad del contenido favorece, a su vez, la socialización de las luchas vinculándolas a prácticas concretas. Será poniendo en primer lugar a las prácticas (amplificándolas, reconociéndolas y legitimándolas) que podrá alimentarse toda la comunidad de esos saberes construidos en las luchas (aunque sea sólo parte de la comunidad la que participe de esas iniciativas). Es la socialización de las luchas a partir del campo educativo permitiendo su empoderamiento y de lxs sujetxs que las habitan y de los saberes que se construyen.

Desde la radicalidad de los contenidos es fundamental reconocer, recuperar y trabajar desde y con los movimientos sociales ya que la formación humana es inseparable de la producción más básica de la existencia y es en los movimientos sociales donde lxs sujetxs se descubren y se aprenden como sujetxs de derechos. $\left(\right.$ Arroyo, 2003) ${ }^{6}$

En las prácticas pedagógicas concretas los contenidos radicales resignifican la escuela y su sentido, generando espacios más participativos y cooperativos ya que son saberes que se construyen en las luchas que son colectivas. Los contenidos por su carácter radical se construyen y se socializan en directa vinculación con lxs estudiantes y con los desafíos que deben enfrentar, por lo cual, el sentido para su aprendizaje es inherente a sí mismo. A su vez, la socialización y producción de estos saberes de manera colectiva, permite su reconstrucción permanente dando cuenta de la flexibilidad de los mismos y de su permanente transformación, de la mano de la transformación social.

La perspectiva trabajada encontrará en el aprendizaje por la investigación una metodología afín que permitirá construir espacios de diálogo de saberes desde su construcción hasta su socialización. Se trata de una concepción curricular que parte de la idea de que el curriculum es abierto y flexible y que se estructura sobre problemáticas y está basado en lo aprendido por los estudiantes y no en la enseñanza del profesor.

En este marco, cobra valor la perspectiva del "curriculumfos-feito" como aquel que es construido a medida que se desarrolla por medio de las problemáticas definidas colectivamente por los estudiantes a partir del cotidiano y del contexto sociocultural y económico en que están insertos (Faria, 2018) ${ }^{7}$.

\section{El CURRICULUM COMO ESPACIO DE RESTITUCIÓN}

A partir de la sociología de la ausencias y vinculándola con el campo curricular, podemos ver que esas construcciones de ausencias responden a relaciones de poder que atraviesan los conocimientos y que reproducen el sistema de divisiones entre lo visible e invisible, lo que puede pensarse y lo que no, los actores, prácticas y conocimientos que llegan a la escuela y cuáles quedan en el camino o ni siquiera emergen.

En las prácticas específicas vinculadas al campo curricular, el identificar las ausencias que se produjeron alrededor de los actores, prácticas y conocimientos permite reflexionar sobre las relaciones de poder en que están insertos y será necesario que estas relaciones se evidencien para lograr la restitución de esxs "ausentes".

Ver al curriculum como espacio de restitución es acercarse desde la sociología de las ausencias donde esas ausencias creadas se recuperan y a partir del trabajo de reflexión e historización que permite establecer las relaciones de poder que las invisibilizaron, son restituidas. Por lo tanto, el curriculum será espacio de restitución cuando las ausencias creadas se identifiquen como tales y logren establecerse las relaciones 
necesarias con las condiciones de producción que les dieron origen. Esas ausencias fueron creadas porque afectaban las relaciones de poder hegemónicas que en cierto contexto histórico fueron construidas y se reproducen. Se trata de saberes contrahegemónicos que al restituirse pueden, a su vez, recuperar su identidad insurgente y abonar las luchas actuales frente a la colonialidad, el patriarcado y el capitalismo.

La restitución de estos otros saberes, actores, lugares, historias y memorias permitirá ampliar el horizonte de posibilidades y alternativas históricas, presentes y futuras, desde una práctica activa frente a la construcción de conocimientos. Son lxs sujetxs, quienes a través de este proceso de reflexión y restitución, se comprometen con la deconstrucción de las relaciones de poder que atraviesan el saber y reconstruyen otras genealogías posibles.

El curriculum como espacio de restitución permite reconocerlo como espacio de disputa en el que cierto orden de jerarquías, asimetrías y silencios producidos históricamente pueden dar lugar a un nuevo orden en el que los conflictos se expliciten y se establezcan relaciones de copresencia entre los saberes y las distintas formas de ser y estar en el mundo posibles, presentes y pasadas.

\section{Al CURRICULUM Y MÁS ALLÁ}

Todo proceso educativo, formal o informal, no puede ignorar cómo incorporar las formas concretas de socialización, de aprendizaje, de formación y deformación a que están sometidos los educandos. Ignorar esa realidad y cerrarnos en "nuestras" cuestiones curriculares y didácticas, terminará por aislar los procesos didácticos escolares de los determinantes procesos socializadores en que los sectores populares se reproducen desde la infancia. (Arroyo, 2003, p. 33)

A través de las categorías propuestas referidas a la colonialidad curricular, la potencialidad curricular, la radicalidad de los contenidos y el costo de oportunidad curricular se procuró poner en común otras posibilidades para pensar el diseño, la implementación y la evaluación de materiales curriculares desde las Epistemologías del Sur.

Los antecedentes teóricos nos permitieron reconocer recorridos diversos que denuncian la colonialidad del saber y la naturalización de cierto orden hegemónico presentado como único posible, las geopolíticas y legados coloniales del conocimiento y las políticas del conocimiento y epistemologías dominantes inscriptas en ciertas relaciones de poder establecidas.

A su vez, estos recorridos nos permiten pensar las relaciones entre la educación y las luchas sociales, las posibilidades de pensamientos contrahegemónicos que circulen y se potencien en espacios educativos descolonizadores, donde se valoricen y afirmen las diferencias. Espacios en los que se dé lugar a la polifonía, a la recuperación de alternativas pedagógicas negadas históricamente, donde se transgredan y desafíen los límites existentes y se habiliten nuevas lecturas y escrituras del mundo. Espacios más colaborativos, solidarios y participativos.

En este contexto, identificar la colonialidad curricular que atraviesa los materiales curriculares nos permite interpelar las relaciones de poder en que se inscriben, la impronta eurocéntrica, capitalista, patriarcal y colonial que puede primar y, a partir de la sociología de las ausencias, identificar las maneras en que opera para producir no existencias, silencios y negaciones.

Reflexionar colectivamente sobre el costo de oportunidad curricular nos permite visibilizar las múltiples pérdidas de saberes, conocimientos y relaciones con las cuales no nos ponemos en contacto e impiden el reconocimiento de otras formas de ser y estar en el mundo que podrían construir otros horizontes posibles y problematizar nuestro propio mundo.

El compromiso frente a la potencialidad curricular como la capacidad que el campo curricular tiene de poner en tensión las relaciones existentes en la sociedad, desde sus posibilidades estratégicas de intervención, permitirá vincularlo con el campo de las luchas sociales que se libran por la transformación social de un orden que es considerado injusto, desigual, capitalista, patriarcal y colonial. 
Finalmente, la radicalidad de los contenidos promueve su interpelación a partir del impacto que tienen en las comunidades y sus procesos identitarios desde los propios desafíos que enfrentan en sus territorios. No están solo vinculados a saberes teóricos sino que parten del reconocimiento de otras sociabilidades, otras relaciones insurgentes entre actores diversos y diferentes formas de organización social, política y económica.

El curriculum como espacio de disputas, entramado de luchas sociales, imposiciones y resistencias, también puede ser pensado como espacio de restitución donde las ausencias creadas se recuperan y a partir del trabajo de reflexión e historización son problematizadas y restituidas.

Si bien la colonialidad curricular es la lógica que atraviesa el campo, reconocer y comprometerse con la potencialidad curricular, a partir de promover la búsqueda y socialización de contenidos radicales, entre otras estrategias, permitirá construir espacios de formación más participativos y cooperativos y mitigar los costos de oportunidad curricular que se presentan al no desafiar la lógica imperante.

Diseñar, implementar y evaluar materiales desde una Epistemología del Sur, como camino hacia la descolonización educativa, permitirá desarrollar desde el campo curricular, la lucha hacia la decolonialidad

y dialogar / traccionar las luchas que se desarrollan en el campo social. Es “al curriculum y más allá” porque la potencialidad curricular nos permite pensar que estas transformaciones son curriculares pero impactan en y devienen de la vida de las personas y se entraman en las luchas por una mayor justicia cognitiva y social. Este es el desafío.

\section{REFERENCIAS}

Antonacci, M. A. (2016). Decolonialidad de cuerpos y saberes: ensayo sobre la diáspora de lo eurocentrado. En J. G. Gandarilla (Ed.), La critica en los márgenes. Hacia una cartografia conceptual para rediscutir la Modernidad (pp. 471-520). México: Ediciones Akal.

Arroyo, M. G. (2003). Pedagogías emmovimento - o que temos a aprender dos MovimentosSociais? Currículo semFronteiras, 3(1). Recuperado de http://www.curriculosemfronteiras.org

Apple, M. (1979). Ideologia y Curriculum. Madrid: Akal.

Apple, M., y Beane, J. (comp.) (2000). Escuelas democráticas. Madrid: Morata.

Benedito, E., Santos, J. J. R., y Souza, J. B. (2016). Currìculo e relacoesetnicorraciais: a implementacao da disciplina "histórica da cultura afro-brasileira" no municipio de Jequié / Bahia. Revista e-Curiculum, 14(04), 1288-1308. Recuperado de http://revistas.pucsp.br/index.php/curriculum

Bergamaschi, M.A., y Menezes, A. L. T. (2016). Crianças indígenas, educação, escola e interculturalidade. Revista eCuriculum, 14(02), 741-764. Recuperado de http://revistas.pucsp.br/index.php/curriculum

Caffentzis, G., y Federici, S. (2015). Comunes contra y más allá del capitalismo. El Aplante. Revista de Estudios Comunitarios, 1(1), 51-72. Recuperado de https://horizontescomunitarios.files.wordpress.com/2017/01/elap antle.pdf

Cunha, K.S., y Da Silva, J. D. P. (2016). Sobre base e bases curriculares, nacionais, comuns: de que currículo estamos falando? Revista e-Curiculum, 14(04), 1236-1257. Recuperado de http://revistas.pucsp.br/index.php/curricul um

Da Silva, T. T. (2001). Espacios de Identidad. Nuevas visiones sobre el curriculum. Barcelona: Octaedro.

De Alba, A. (1995). Curriculum: Crisis, mito y perspectivas. Buenos Aires: Miño y Dávila Editores.

De Sousa Santos, B. (2010). Refundación del Estado en América Latina: perspectivas desde una epistemología del Sur. Lima: Instituto Internacional de Derecho y Sociedad.

De Sousa Santos, B (2018a). Introducción a las Epistemologías del Sur. En Construyendo las Epistemologías del Sur. Para un pensamiento alternativo de alternativas. Vol. 1. (pp. 303-342). Buenos Aires: CLACSO.

De Sousa Santos, B (2018b). Hacia una universidad polifo\#nica y comprometida: pluriversidad y subversidad. En Construyendo las Epistemologias del Sur. Para un pensamiento alternativo de alternativas. Vol. 2. (pp. 699-734). Buenos Aires: CLACSO. 
Díaz M. C. (2010). Hacia una pedagogía en clave decolonial: entre aperturas, búsquedas y posibilidades. Tabula Rasa, (13), 217-233. http://dx.doi.org/10.25058/20112742.410

Dietz, G. y Mateos Cortes, L.C. (2011) Interculturalidad y educación intercultural en México. Un análisis de los discursos nacionales e internacionales en su impacto en los modelos educativos mexicanos. México. SEP / CGEIB.

Faria, I. F. (2018). Por uma Educação Indígena Superior: a experiência do Curso de Licenciatura Indígena. Políticas Educacionais e Desenvolvimento Sustentável da Universidade Federal do Amazonas. En Mato, D. (coord.), Educación Superior y Pueblos Indigenas y Afrodescendientes en América Latina (pp. 183-198). Buenos Aires: UNTREF.

González Martínez, L. (2006). La Pedagogía Crítica de Henry A. Giroux. Revista Electrónica Sinéctica, (29), 83-87. Recuperado de https://www.redalyc.org/pdf/998/99815739014.pdf

Gutierrez, R. y Salazar Lohman, H. (2015). Reproducción comunitaria de la vida. Pensando la trans-formación social en el presente. El Aplante. Revista de Estudios Comunitarios, 1(1), 15-50. Recuperado de https://horizontescom unitarios.files.wordpress.com/2017/01/elapantle.pdf

Lander, E. (comp.) (2000). La colonialidad del saber: eurocentrismo y ciencias sociales. Perspectivas latinoamericanas. Buenos Aires: CLACSO.

Lao-Montes, A. (2013). Empoderamiento, descolonización y democracia sustantiva. Afinando principios éticopolíticos para las diásporas Afroamericanas. Revista CS. (12) 53-84. Recuperado de https://www.redalyc.org/p df/4763/476348375002.pdf

Lenkersdorf, C. (2003). Lenguas y Diálogo intercultural. Revista Electrónica de Estudios Filológicos, (6), Recuperado de https://www.um.es/tonosdigital/znum6/estudios/Lenkersdorf.htm

Peñuela C. D. M. (2009). Pedagogía decolonial y educación comunitaria: una posibilidad ético-política. Pedagogía y Saberes, (30), 39-46. doi: https://doi.org/10.17227/01212494.30pys39.46

Plá, S. (2016). Currículo, historia y justicia social. Estudio comparativo en América Latina. Revista Colombiana de educación (71), 53-77. https://doi.org/10.17227/01203916.71rce53.77

Prado, A. (2004). América Latina: Educación y Colonialidad. Estudios Sociológicos, 22(1), 151-168.

Puiggrós, A. (1990). Sujetos, disciplina y curriculum en los orígenes del sistema educativo argentino. Buenos Aires: Galerna.

Quijano, A. (2014). Colonialidad del Poder y Clasificación Social. En Cuestiones y horizontes: de la dependencia histórico-estructural a la colonialidad y descolonialidad del poder (pp. 285-327). Buenos Aires: CLACSO.

Quijano, A. (2000) Colonialidad del Poder y Clasificación Social. Originalmente en Festchrift for Immanuel Wallerstein, Journal of World-Systems Research, Special Issue. Giovanni Arrighi and Walter Goldfrank, eds. Colorado, USA. Vol. VI, No. 2, Fall/Winter

Terigi, F. (1999). Curriculum. Itinerarios para aprehender un territorio. Buenos Aires: Santillana.

Walsh, C. (2007). Interculturalidad, colonialidad y educación. Revista Educación y Pedagogía. 19 (48), 27-43. Recuperado de https://flacsoandes.edu.ec/sites/default/files/agora/files/1265909654.interculturalidad_colo nialidad_y_educacion_0.pdf

Walsh, C. (2008). Interculturalidad, plurinacionalidad y decolonialidad: las insurgencias político-epistémicas de refundar el Estado. Tabula Rasa, (9), 131-152. Recuperado de http://revistatabularasa.org/numero-9/08walsh .pdf

Walsh, C. (2009). Interculturalidad, Estado, Sociedad: Luchas (de)coloniales de nuestra época. Quito: Ediciones AbyaYala.

\section{Notas}

1 De Sousa Santos refiere a las epistemologías del sur como la producción y validación de los conocimientos anclados en las experiencias de resistencia de todos los grupos sociales que sistemáticamente han sufrido la injusticia, la opresión y la destrucción causada por el capitalismo, el colonialismo y el patriarcado. 
2 Estas reflexiones no provienen de un análisis sistemático de datos y evidencia empírica, sino de reflexiones colectivas entre lxsdiversxs actores que habitamos los procesos de enseñanza y de aprendizaje y se nutre de las prácticas pedagógicas.

3 En relación a la ortografía del término curriculum se mantendrá la escritura del latin, origen del término, cuya correcta escritura en singular es "el curriculum" y el plural "los curricula", sin tilde en ambos casos.

4 Anibal Quijano explica a la colonialidad del poder como un elemento constitutivo y específico del patrón mundial de poder capitalista, que se origina y mundializa a partir de la "Conquista de América". Implica la imposición de una clasificación racial / étnica de la población del mundo que opera en cada uno de los planos, ámbitos y dimensiones materiales y subjetivas de la existencia cotidiana.

5 Traducción propia del portugués.

6 Traducción propia del portugués.

7 Traducción propia del portugués. 